\title{
Variable selection via the adaptive elastic net: mathematics success of the students in Singapore and Turkey
}

\author{
Kadriye Hilal Topal ${ }^{1}$ \\ 1 Nisantasi University, Department of Computer Programming, Turkey e-mail: hilal.topal@nisantasi.edu.tr
}

\begin{abstract}
The quality of education is crucial for its competitiveness in the developing world. International tests are organized at regular intervals to measure the quality of education and to see the place in the ranking of countries. The surveys on these examinations have provided a large number of variables that can be effective on the test scores, including family, teacher, school and course equipment and information communication technologies, etc. The important question is which variables are relevant for student achievement in these tests. The barriers of mathematics success of Turkish students in the TIMSS (International Mathematics and Science Study) exam were investigated and compared their status with Singaporean students who took part in at the top of the ranking in the exam. To do this, the adaptive elastic net which is one of the regularized regression methods was applied and compared their prediction accuracy according to three different alpha levels $[0.1 ; 0.5 ; 0.9]$. The findings indicate that individual, institutional, socioeconomic factors such as talented teachers, less homework, less extensive textbooks, and lessons that improving cognitive ability; home education resources as well as technological factors are effective in the educational performances of countries. The findings suggest that, a technology-oriented education system and these individual, institutional, socioeconomic factors can help increase the success of students in Turkey along with other countries which are having similar experiences in international tests.
\end{abstract}

Keywords: Adaptive Elastic Net, Education, Machine Learning, Oracle Properties, TIMSSS

JEL Codes: A20, I21, C55

Citation: TOPAL, K. H. (2021). Variable Selection via the Adaptive Elastic Net: Mathematics Success of the Students in Singapore and Turkey Journal of Applied Microeconometrics (JAME). 1(1), 40-54, DOI: 10.53753/jame.1.1.04 


\section{INTRODUCTION}

Education is a key factor in the development of individuals and communities. For this important reason, various tests are conducted to see the educational status of countries and their rankings among other countries. These tests are important resources for individuals and institutions in determining the factors affecting the educational performance of countries and formulating educational policies. The $3^{\text {rd }}$ must be removed. Trends in International Mathematics and Science Study (TIMSS) is one of the several international tests which measures educational performance. Understanding this test is very important in order to improve education from various aspects.

The huge educational data and information about students' and families' backgrounds and school characteristics can be obtained from the TIMSS test for researchers. It is applied to the $4^{\text {th }}$ grade students aged 9.5 and older and the $8^{\text {th }}$ grade students aged 13.5 and older, according to the International Standard Classification of Education (ISCED) developed by United Nations Educational, Scientific and Cultural Organization (UNESCO) (Martin et al. 2016). This is a test where students are asked various questions about their social and school lives, basic demographic information, home and environmental questions, school atmosphere, self-understanding, mathematics, and scientific studies as well as mathematics and science curriculum questions. Many different educational inputs affect educational performances of the countries directly or indirectly. The variable selection is a very important issue for determining variables, which are important for prediction of educational performances.

In the machine learning literature, least absolute shrinkage and selection operator (LASSO) and elastic net regression are the most commonly utilized variable selection and regularization methods that detect the subset of the "true" variable set of model and the optimal estimation rate. However, such method does not have any oracle properties: a) the asymptotic normality and b) the consistency in the variable selection. Zou (2006) proved that once a variable is selected from a set of considered variables, all variables are automatically selected from this set while constructing the model because of oracle properties of the adaptive LASSO procedure. However, because of the drawback of the adaptive LASSO in the case of collinearity, the adaptive elastic net method was proposed by Zou and Zhang (2009). The adaptive elastic net method can be employed to overcome the collinearity problem that might occur in variables by eliminating the parameter inconsistency and the variable selection bias as result of its oracle properties.

The aim of the study is to determine the effective variables on the student achievement of TIMSS in Turkey and Singapore to reveal the similarities and differences of the factors of educational performances between these two countries. The LASSO regression is a good variable selection method. The Elastic net regression takes into account multicollinearity (it means that there are high linear correlations between two or more explanatory variables) while performing variable selection. The adaptive elastic net regression has both these properties of lasso and elastic net regressions as well as oracle properties. For these reasons, the LASSO elastic net and the adaptive elastic net regression methods are applied on large-scale TIMSS data and are employed to compare forecasting accuracies of these models.

Table 1. The $8^{\text {th }}$ Grade TIMSS Mathematics Performance by Years: Turkey and Singapore

\begin{tabular}{lccccc}
\hline Year & $\begin{array}{c}\text { Number of } \\
\text { participant } \\
\text { Countries }\end{array}$ & $\begin{array}{c}\text { Mathematics Score } \\
\text { of TR }\end{array}$ & Rank(TR) & $\begin{array}{c}\text { Mathematics Score } \\
\text { of SGP }\end{array}$ & Rank(SGP) \\
\hline 1995 & 41 & - & - & 643 & 1 \\
1999 & 38 & 429 & 31 & 604 & 1 \\
2003 & 46 & - & - & 605 & 1 \\
2007 & 50 & 432 & 30 & 593 & 3 \\
2011 & 45 & 452 & 24 & 611 & 2 \\
2015 & 50 & 458 & 24 & 621 & 1 \\
\hline
\end{tabular}

Table 1 shows the $8^{\text {th }}$ grade TIMSS mathematics performance by years for Turkey (TR) and-Singapore (SGP). Turkey participated in 1999 for the first time in the TIMSS test and took 429 points. The rank of success of Turkey in mathematics score was 31 out of 38 countries. While Singapore has the highest achieving students in international education rankings with its teenagers coming at the top in mathematics tests, Turkey is still not good enough. 
There are a few studies in the literature analyzing the TIMSS exam results through machine learning methods. For example, Filiz and Öz (2020) applied educational data mining on TIMSS 2015 the $8^{\text {th }}$ grade Turkish students' data. They aimed to find best performer algorithm to classifying students' mathematic success and extract important features on success. The best algorithms were found as logistic regression and support vector machines. The "home educational resources", "student confident in mathematics" and "mathematics achievement too low for estimation" were selected as the most effective features on success. Filiz and Öz (2019) were purposed to find the algorithms that are the most appropriate for classifying the successes of students, especially in science subjects, and to determine the significant factors on this success by using the results of TIMSS $20158^{\text {th }}$ grade Turkish students' data. Logistic regression and support vector machines were found as the most appropriate methods. The "computer tablet shared", "extra lessons last 12 month", "extra lessons how many month", "how far in education do you expect to go", "home educational resources", and "student confident in science" were selected as the most significant features in science success. Yoo (2018) utilized an elastic net method with a logistic regression model to determine the effective factors on TIMSS 2011 Korean $4^{\text {th }}$ grade students' mathematics achievement. Among 162 TIMSS variables, 12 students and 5 teacher variables were selected through the elastic net method. Depren et al. (2017) employed a decision tree, a bayesian network, a logistic regression and neural network methods to determinate the TIMSS 2011 mathematics achievement factors for the $8^{\text {th }}$ grade Turkish students. They found that the logistic regression was the best algorithm for the selection of the factors. Yoo and Rho (2017) applied random forest which was a supervised machine learning algorithm to determine the significant factors for the TIMSS 2015 Korean $8^{\text {th }}$ graders' student, teacher, and school datasets such as "students' extra lessons or tutoring the last 12 months", "genlyears been teaching" and "total instructional hours per year". The highest relevant variables of TIMSS were found in the variables obtained from students' datasets.

In Yoo and Rho (2017) study, a data set with a total of 413 variables, consisting of 147 students, 175 teachers and 91 school variables, was used to investigate the important variables that affect the mathematics achievement of Korean students. 17 student variables were found possessing more than 20 variable significance. These variables measured students' math self-efficacy, confidence, and interest, math extra lessons, science self-efficacy, selfconfidence, time spent on science homework and desire for education, the amount of books in the house and the education level of the father.

This study differs from other studies in the literature in terms of using adaptive elastic net regression, which is an advanced method enjoys oracle properties, in investigating the factors that determine the success of TIMMS. In addition, Singapore, which is a very successful country in TIMSS exams, and Turkey, which has average score, have been compared and their similarities and differences have been revealed.

\section{METHODOLOGY}

\subsection{Adaptive Elastic Net}

The least squares (LS) is an estimation method that gives all nonzero coefficients under fundamental assumptions such as linearity, homoscedasticity, independence and normality. In the literature, the subset of significant effective variables on the response variable utilizes the best-subset selection and stepwise selection procedures. Unfortunately, in datasets with a large number of explanatory variables, the best-subset selection procedure is infeasible since there is a need for many models to be estimated (Breiman 1995). In stepwise selection, the number of potential models to be estimated is less than in the best subset selection. However, this does not indicate that it is a more suitable model selection method, as stochastic errors are ignored in the variable selection step (Fan and Li 2004). Moreover, this can result in a locally optimal solution instead of global optimal solution especially if explanatory variables are associated (Shen and Ye 2002). Hoerl and Kennard (1970) proposed the ridge regression which is a superior method compared to the LS in terms of variance reduction when the multicollinearity problem arises among variables of large datasets. However, the ridge regression coefficients are not equal to zero since the method is not a variable selection procedure.

The LASSO method developed by Tibshirani (1996) provides a consistent selection of a subset of the relevant variables and predicted of model coefficients in a model. The LASSO estimator is as follows; 


$$
\hat{\beta}_{\text {LASSO }}=\arg \min \left[\sum_{i=1}^{n}\left(Y_{i}-\beta_{0}-\sum_{j=1}^{p} X_{i j} \beta_{j}\right)^{2}+\lambda \sum_{j=1}^{p}\left|\beta_{j}\right|\right]
$$

Elastic net equation is written instead of LASSO equation. The LASSO equation must be written. Where $\lambda$ is a tuning parameter of penalty $|\beta \mathrm{j}|$, is a 11 penalty that is obtained by penalizing the absolute coefficients of the variables included in the model. According to Fan and $\mathrm{Li}$ (2001), there were two main problems of LASSO. The first problem was the shrinkage procedure of LASSO causing biased estimates of the large coefficients with an unacceptable estimation risk. The second problem was the variable selection of LASSO being automatic because the 11 penalty is not differentiable since it is singular at the origin. Zou (2006) proved that the LASSO is not consistent in model selection under mild conditions. To overcome such problems of LASSO, Zou (2006) developed the adaptive LASSO. This type of LASSO enjoys the oracle properties. The LASSO gains the oracle properties thanks to the optimal weights.

Elastic net method proposed by Zou and Hastie (2005) to overcome the parameter bias of LASSO in the case of collinearity. The elastic net estimator is as follows;

$$
\hat{\beta}_{(\text {Elastic Net })}=\arg \min \left[\frac{1}{2 n} \sum_{i=1}^{n}\left(Y_{i}-\beta_{0}-\sum_{j=1}^{p} X_{i j} \beta_{j}\right)^{2}+\lambda\left(\frac{1-\alpha}{2} \sum_{j=1}^{p} \beta_{j}^{2}+\alpha \sum_{j=1}^{p}\left|\beta_{j}\right|\right)\right]
$$

Where $\lambda$ and $\alpha$ are the tuning parameter of $\ell_{1}$ and $\ell_{2}$ penalty, respectively. $\left|\beta_{i}\right|$ is $\ell_{1}$ penalty, $\left|\beta^{2}\right|$ is the $\ell_{2}$ penalty which is obtained by penalizing the squared coefficients of the variables included in the model. The elastic net method establish a regression model taking advantage of $\ell_{2}$ and $\ell_{1}$ penalty of ridge and LASSO. Thus, the method simultaneously can make automatic variable selection and continuous shrinkage, and it can select groups of correlated variables. Nevertheless, this method does not enjoy the oracle properties such as parameter selection stability and normality. As a result, a significant bias can occur in the elastic net estimators.

Zou and Zhang (2009) developed the adaptive elastic net method, which enjoys the oracle properties and calculates the adaptive weights utilizing the elastic net estimators to overcome the problems of the elastic net.

The adaptive elastic net is a combination of $\ell_{2}$ and $\ell_{1}$ penalty. When the estimator matrix is sparse or ill-conditioned, the adaptive elastic net regression provides variable selection consistency as well as parameter stability. In addition, the $\ell_{2}$ penalty deals with the trouble effects of strong collinearity (Zou and Zhang, 2009). Therefore, this method outperforms the elastic net. The estimator of the adaptive elastic net regression is as follows;

$$
\begin{aligned}
& \hat{\beta}_{\left(\begin{array}{c}
\text { Adaptive } \\
\text { ElasticNet }
\end{array}\right)}=\left(1+\frac{\lambda_{2}}{n}\right)\left[\underset{\beta}{\operatorname{argmin}}\left\|y-\sum_{j=1}^{p} x_{j} \beta_{j}\right\|^{2}+\lambda_{2} \sum_{j=1}^{p} \beta_{j}^{2}+\lambda_{1}^{*} \sum_{j=1}^{p} \widehat{w}_{j}\left|\beta_{j}\right|\right] \\
& \text { Subject to } \widehat{w}_{j}=\frac{1}{\left(\left|\widehat{\beta}_{j}^{(\text {enet })}\right|\right)^{\gamma}}, j=1, \ldots, p \text {. }
\end{aligned}
$$

Where $\lambda_{2}$ represents the tuning parameter of $\ell_{2}$ regulation, $\lambda_{1}{ }^{*}$ represents the tuning parameter of $\ell_{1}$ regulation, $\hat{\mathrm{w}}_{\mathrm{j}}$ is adaptive weight obtained through elastic net coefficients, is a positive constant calculated by $\gamma=\frac{2 v}{1-v}$ and $v=\lim _{n \rightarrow \infty} \frac{\log (p)}{\log (n)}$. Tunning parameter of the model function is as follows;

$$
P_{\alpha}=(1-\alpha)|\beta|_{1}+\alpha|\beta|_{2}^{2}=\lambda_{2}|\beta|_{2}^{2}+\lambda_{1}\|\beta\|_{1}
$$

Here $\alpha=\frac{\lambda_{2}}{\lambda_{1}+\lambda_{2}}$ and $\alpha \in(0,1)$. After Zou and Zhang (2009)'s elastic net prediction weights, Jiratchayut and Bumrungsup (2015) set rescaled the elastic net estimator with to be three estimators. Here is a parameter given relations between shrinkage parameters. Adaptive elastic net regression, unlike conventional regression methods, enables superior results in the analysis as it applies a reduction procedure for both variable selection and minimum 
variance estimators (Jiratchayut and Bumrungsup, 2015).

\section{RESULTS}

\subsection{Data Set}

The dataset was obtained from the TIMSS international database for 2015 . The data used the $8^{\text {th }}$ grade student background (BSGM6) questionnaires for Turkey and Singapore. According to the TIMSS 2015 survey, the number of participated students was 6079 and 6116 respectively for Turkey and Singapore. The irrelevant variables were excluded and applied the cleaning process through listwise deletion to handle with the missing data. The contents of TIMSS mathematics assessment are algebra, data and chance, geometry, number, and cognitive areas (knowing, applying, reasoning). The dependent variable was the average of these values.

\subsection{Empirical Findings}

The LASSO elastic net and adaptive elastic net regression methods (at three alpha level) which are the machine learning technique has been applied to Turkey and Singapore's 2015 TIMSS Survey datasets. All methods carried out in R software using packages msaenet for adaptive elastic net, glmnet for LASSO and elastic net. First, I divided the dataset into training and test datasets with a ratio of 80:20. The dataset of Turkey consists of 3340 students by 2672 training and 668 test data whereas Singapore has 3318 number of students with 2654 training and 664 test data. The training dataset was utilized to predict model parameters and hyperparameters. The test dataset was utilized to validate forecasting accuracy of the models with these parameters and hyperparameters. Prediction accuracy measures how close the forecasting values are to the data employed in the estimation except of sample datasets. It informs whether the parameters are optimally selected and whether the best model is constructed. The validation of the hyperparameters of this constructed best model is measured by using the test dataset. The errorbased criteria which are the root mean square error (MSE), the mean absolute error (MAE), and R-squared were used for prediction of hyperparameter and validation. After the detection and validation of hyperparameters, the regression coefficients were estimated through the utilization of the adaptive elastic net methods for both data sets.

Following the study of Jiratchayut and Bumrungsup (2015), three different approaches were applied for the detection of the alpha values, $[0.1,0.5,0.9]$, and then the weighting of the adaptive elastic net was utilized. Finally, the most appropriate alpha value was chosen based on the prediction accuracy.

Table 2. Prediction and Forecasting Accuracy Table

\begin{tabular}{|c|c|c|c|c|c|c|c|}
\hline \multirow{2}{*}{ Country } & \multirow{2}{*}{ weight } & \multicolumn{3}{|c|}{ Train Sample } & \multicolumn{3}{|c|}{ Test Sample } \\
\hline & & $R M S E$ & $M A E$ & $R$-squared & $R M S E$ & $M A E$ & $R$-squared \\
\hline \multirow{4}{*}{ TR } & Lasso & 0.123201 & 0.098334 & 0.63 & 0.126347 & 0.100251 & 0.61 \\
\hline & Elastic Net & 0.127758 & 0.102687 & 0.61 & 0.131681 & 0.104535 & 0.58 \\
\hline & Adaptive Elastic Net(0.1) & 0.115433 & 0.092498 & 0.68 & 0.114224 & 0.091378 & 0.67 \\
\hline & Adaptive Elastic Net(0.9) & 0.115388 & 0.092514 & 0.68 & 0.114209 & 0.091341 & 0.67 \\
\hline \multirow[b]{3}{*}{ SGP } & Lasso & 0.093833 & 0.071983 & 0.44 & 0.093934 & 0.069866 & 0.46 \\
\hline & Elastic Net & 0.097089 & 0.074330 & 0.40 & 0.097025 & 0.072925 & 0.42 \\
\hline & Adaptive Elastic Net(0.1) & 0.082870 & 0.063779 & 0.57 & 0.088314 & 0.068796 & 0.47 \\
\hline
\end{tabular}

Notes: (i) In the adaptive elastic net method, penalty parameters, $\lambda$ and $\alpha$ were optained by k-fold cross validation; $\mathrm{k}$ was chosen as 10 .

(ii) Adaptive elastic net results were obtained according to $\alpha=(0.1,0.5,0.9)$ values.

(iii) $R M S E=\sqrt{\frac{\sum_{i=1}^{n}\left(y_{t}-\hat{y}_{t}\right)^{2}}{n}}, M A E=\frac{\sum_{i=1}^{n}\left|y_{t}-\hat{y}_{t}\right|}{n}, R-$ squared $=\frac{\sum_{i=1}^{n}\left(\hat{y}_{t}-\bar{y}_{t}\right)^{2}}{\sum_{i=1}^{n}\left(y_{t}-\bar{y}_{t}\right)^{2}}$ 
Table 2 shows the RMSE, MAE, and R-squared results based on errors obtained from training and test sample purposes for two countries and each methods. The RMSE, MAE and R-squared values of TR are [0.115388, $0.092514,0.68]$ for training data and $[0.11421,0.09134,0.67]$ for test data; the values of SGP are [0.082808, $0.063775,0.58]$ for training data and $[0.08830,0.06875,0.47]$ for test data. As presented in Table 2, the adaptive elastic net regression rescaled with an alpha level of [0.9] is the most accurate method for both countries.

According to the estimation results, for the model for Turkey, 60 non-zero coefficients were estimated from 98 variables by the adaptive elastic net method with the alpha level 0.9 whereas for the model for Singapore, 68 non-zero coefficients were estimated from the 100 variables by the method with the alpha level 0.9 . The results of adaptive elastic net regression are presented in Table 3.

Table 3. Results of the Adaptive Elastic Net

\begin{tabular}{|c|c|c|c|c|}
\hline Variable & Definition & & $\begin{array}{c}\text { TR } \\
\text { Adaptive Elastic } \\
\text { Net(0.9) }\end{array}$ & $\begin{array}{c}\text { SGP } \\
\text { Adaptive Elastic } \\
\text { Net(0.9) }\end{array}$ \\
\hline ITSEX & Sex Of Students & (1 if female, otherwise 0 ) & -0.0116 & -0.0090 \\
\hline BSBG03 & Gen $\backslash$ Often Speak $<$ Lang Of Test $>$ At Home & 1(always) to 4(Never) & -0.0266 & 0 \\
\hline BSBG04 & Gen $\backslash$ Amount Of Books in Your Home & $1(0-10)$ to $4($ More than 200$)$ & 0.0149 & 0.0079 \\
\hline BSBG05 & Gen $\backslash$ Digital information Devices & 1 (None) to 4 (More than 10$)$ & 0.0050 & 0.0085 \\
\hline BSBG06A & Gen $\backslash$ Home Possess $\backslash$ Computer Tablet Own & (1 if yes, otherwise 0 ) & 0 & 0.0048 \\
\hline BSBG06B & Gen $\backslash$ Home Possess $\backslash$ Computer Tablet Shared & (1 if yes, otherwise 0 ) & 0.0304 & 0.0180 \\
\hline BSBG06C & Gen $\backslash$ Home Possess Study Desk & (1 if yes, otherwise 0 ) & 0.0058 & 0.0091 \\
\hline BSBG06E & Gen\Home Possess internet Connection & ( 1 if yes, otherwise 0 ) & 0 & 0.0291 \\
\hline BSBG06F & Gen\Home Possess \Own Mobile Phone & (1 if yes, otherwise 0 ) & 0.0332 & 0 \\
\hline BSBG06G & Gen\Home Possess \Gaming System & (1 if yes, otherwise 0 ) & 0 & -0.0081 \\
\hline BSBG06H & Gen $\backslash$ Home Possess $\backslash<$ Country Specific $>$ & (1 if yes, otherwise 0 ) & 0.0074 & 0.0142 \\
\hline BSBG06I & Gen $\backslash$ Home Possess $\backslash<$ Country Specific $>$ & (1 if yes, otherwise 0 ) & -0.006 & 0 \\
\hline BSBG06J & Gen $\backslash$ Home Possess $\backslash<$ Country Specific $>$ & (1 if yes, otherwise 0 ) & 0.0186 & 0.0221 \\
\hline BSBG06K & Gen $\backslash$ Home Possess $\backslash<$ Country Specific $>$ & ( 1 if yes, otherwise 0 ) & 0 & -0.0162 \\
\hline BSBG07A & GenไHighest Lvl Of Edu Of Mother & 1(Primary/lowerSecondary/None) to 7(Postgraduate) & 0.0043 & 0.0064 \\
\hline BSBG07B & Gen\Highest Lvl Of Edu Of Father & 1(Primary/lowerSecondary/None) to 7(Postgraduate) & 0.0072 & 0.0015 \\
\hline BSBG08 & Gen\How Far İn Edu Do You Expect To Go & 1(Lower secondary) to 6(Postgraduate) & 0.0257 & 0.0209 \\
\hline BSBG09A & Gen $\backslash$ Mother Born İn $<$ Country $>$ & (1 if yes, otherwise 0 ) & 0 & -0.0080 \\
\hline BSBG09B & Gen $\mid$ Father Born İ $<$ Country $>$ & (1 if yes, otherwise 0 ) & 0.0282 & -0.0028 \\
\hline BSBG10A & Gen $\backslash$ Born İn $<$ Country $>$ & ( 1 if yes, otherwise 0 ) & 0 & 0.0045 \\
\hline BSBG11 & Gen $\backslash$ About How Often Absent From School & 1 (Once a week or more) to 4 (Never,Almost Never) & 0.0235 & 0.03178 \\
\hline BSBG12 & Gen\How Often Breakfast On School Days & 1(Every Day) to 4(Never,Almost Never) & 0 & -0.0038 \\
\hline BSBG13A & Gen\How Often Use Computer Tablet $\backslash$ Home & $\begin{array}{l}\text { 1(Every day,almost every day) to } 4 \text { (Never,Almost } \\
\text { Never) }\end{array}$ & 0.0089 & 0 \\
\hline BSBG13B & Gen\How Often Use Computer Tablet $\backslash$ School & $\begin{array}{c}\text { 1(Every day,almost every day) to } 4 \text { (Never,Almost } \\
\text { Never) }\end{array}$ & 0.0044 & 0.0012 \\
\hline BSBG13C & Gen\How Often Use Computer Tablet $\backslash$ Other & $\begin{array}{l}\text { 1(Every day,almost every day) to 4(Never,Almost } \\
\text { Never) }\end{array}$ & 0.0033 & 0.0073 \\
\hline BSBG14A & Gen $\backslash$ internet Use $\backslash A c c e s s$ Textbooks & (1 if yes, otherwise 0 ) & -0.0020 & 0 \\
\hline BSBG14B & Genlinternet Use $\backslash$ Access Assignments & ( 1 if yes, otherwise 0 ) & -0.0180 & 0.0302 \\
\hline BSBG14C & Gen internet Use $\backslash$ Collaborate With Classmates & (1 if yes, otherwise 0 ) & 0 & 0.0338 \\
\hline BSBG14D & Gen linternet UselCommunicate With Teacher & ( 1 if yes, otherwise 0 ) & -0.0359 & 0.0039 \\
\hline BSBG14E & Genlinternet UselFind info To Aid in Math & (1 if yes, otherwise 0 ) & -0.0055 & -0.0108 \\
\hline BSBG14F & Genlinternet UselFind info To Aid in Science & (1 if yes, otherwise 0 ) & -0.0127 & 0.0158 \\
\hline BSBG15A & Gen $\backslash$ Agree\Being in School & 1(Agree a lot) to 4(Disagree a lot) & 0.0314 & 0.0114 \\
\hline BSBG15B & Gen $\backslash$ Agree $\backslash$ Safe At School & 1(Agree a lot) to 4(Disagree a lot) & 0 & -0.0066 \\
\hline BSBG15C & Gen $\backslash$ Agree \Belong At School & 1(Agree a lot) to 4(Disagree a lot) & 0.0033 & 0 \\
\hline BSBG15D & Gen $\backslash$ Agree $\backslash$ Like To See Classmates & 1(Agree a lot) to 4(Disagree a lot) & 0.0042 & -0.0023 \\
\hline BSBG15E & Gen $\backslash$ AgreelFair Teachers & 1(Agree a lot) to 4(Disagree a lot) & -0.0194 & 0.0045 \\
\hline BSBG15F & Gen $\backslash$ Agree $\backslash$ Proud To Go To This School & 1(Agree a lot) to 4(Disagree a lot) & 0 & -0.0085 \\
\hline
\end{tabular}




\begin{tabular}{|c|c|c|c|c|}
\hline BSBG15G & Gen $\backslash$ Agree $\backslash$ Learn A Lot & 1(Agree a lot) to 4(Disagree a lot) & 0 & 0.0019 \\
\hline BSBG16A & Gen\How Often \Made Fun Of & 1(At least once a week) to 4 (Never) & 0 & 0.0022 \\
\hline BSBG16B & Gen $\backslash$ How Often $\backslash$ Left Out Of Games & 1(At least once a week) to 4 (Never) & 0.0090 & -0.0044 \\
\hline BSBG16C & Gen\How Often $\backslash$ Spread Lies About Me & 1(At least once a week) to 4 (Never) & 0 & 0.0039 \\
\hline BSBG16D & Gen $\backslash$ How Often $\backslash$ Stole Sth From Me & 1(At least once a week) to 4 (Never) & 0.0018 & 0.0091 \\
\hline BSBG16E & Gen \How Often\Hurt By Others & 1(At least once a week) to 4(Never) & -0.0055 & 0 \\
\hline BSBG16H & Gen $\backslash$ How Often $\backslash$ Posted Embarrassing Things & 1(At least once a week) to 4 (Never) & 0.0144 & -0.0038 \\
\hline BSBG16I & Gen $\backslash$ How Often $\backslash$ Threatened & 1(At least once a week) to 4 (Never) & 0 & 0.0070 \\
\hline BSBM17A & Math $\backslash$ Agree Enjoy Learning Mathematics & 1(Agree a lot) to 4(Disagree a lot) & 0.0041 & -0.0003 \\
\hline BSBM17B & Math $\backslash$ Agree $\backslash$ Wish Have Not To Study Math & 1(Agree a lot) to 4(Disagree a lot) & -0.0095 & 0.0087 \\
\hline BSBM17C & Math $\backslash$ Agree $\backslash$ Math is Boring & 1(Agree a lot) to 4(Disagree a lot) & 0.0034 & 0 \\
\hline BSBM17D & Math $\backslash$ Agree $\mid$ Learn interesting Things & 1(Agree a lot) to 4(Disagree a lot) & 0 & $1.41666 \mathrm{E}-05$ \\
\hline BSBM17F & Math $\backslash$ Agree $\backslash$ Like Numbers & 1(Agree a lot) to 4(Disagree a lot) & 0.0107 & 0 \\
\hline BSBM17G & Math $\backslash$ Agree $\backslash$ Like Math Problems & 1(Agree a lot) to 4(Disagree a lot) & -0.0081 & -0.0100 \\
\hline BSBM17H & Math $\backslash$ Agree LLook Forward To Math Class & 1(Agree a lot) to 4(Disagree a lot) & 0.0198 & 0.0061 \\
\hline BSBM17I & Math $\backslash$ Agree $\backslash$ Favorite Subject & 1(Agree a lot) to 4(Disagree a lot) & -0.0075 & 0 \\
\hline BSBM18A & Math $\backslash$ Agree $\backslash$ Teacher Expects To Do & 1(Agree a lot) to 4(Disagree a lot) & -0.0139 & 0 \\
\hline BSBM18B & Math $\backslash$ Agree $\backslash$ Teacher is Easy To Understand & 1(Agree a lot) to 4(Disagree a lot) & 0 & -0.0063 \\
\hline BSBM18C & Math $\backslash$ Agreelinterested in What Tchr Says & 1(Agree a lot) to 4(Disagree a lot) & -0.0065 & 0.0066 \\
\hline BSBM18D & Math $\backslash$ Agreelinteresting Things To Do & 1(Agree a lot) to 4(Disagree a lot) & 0 & 0.0057 \\
\hline BSBM18E & Math $\backslash$ Agree $\backslash$ Teacher Clear Answers & 1(Agree a lot) to 4(Disagree a lot) & -0.0048 & 0 \\
\hline BSBM18F & Math $\backslash$ Agree $\backslash$ Teacher Explains Good & 1(Agree a lot) to 4(Disagree a lot) & 0 & -0.0016 \\
\hline BSBM18G & Math $\backslash$ Agree $\backslash$ Teacher Shows Learned & 1(Agree a lot) to 4(Disagree a lot) & 0.0098 & 0 \\
\hline BSBM18H & Math $\backslash$ Agree $\backslash$ Different Things To Help & 1(Agree a lot) to 4(Disagree a lot) & 0.0097 & 0.0032 \\
\hline BSBM18I & Math \Agree|Tells How To Do Better & 1(Agree a lot) to 4(Disagree a lot) & 0 & 0.0043 \\
\hline BSBM18J & Math $\backslash$ Agree $\backslash$ Teacher Listens & 1(Agree a lot) to 4(Disagree a lot) & 0 & -0.0045 \\
\hline BSBM19A & Math $\backslash$ Agree Usually Do Well in Math & 1(Agree a lot) to 4(Disagree a lot) & -0.0314 & -0.0092 \\
\hline BSBM19B & Math $\backslash$ AgreelMathematics is More Difficult & 1(Agree a lot) to 4(Disagree a lot) & 0.0214 & 0 \\
\hline BSBM19C & Math $\backslash$ AgreelMathematics Not My Strength & 1(Agree a lot) to 4(Disagree a lot) & 0.0147 & 0 \\
\hline BSBM19D & Math $\backslash$ Agree Learn Quickly in Mathematics & 1(Agree a lot) to 4(Disagree a lot) & -0.0081 & -0.0060 \\
\hline BSBM19E & Math \Agree\Mat Makes Nervous & 1(Agree a lot) to 4(Disagree a lot) & 0.0119 & 0 \\
\hline BSBM19F & Math $\backslash$ Agree $\backslash$ Good At Working Out Problems & 1(Agree a lot) to 4(Disagree a lot) & -0.0072 & -0.007 \\
\hline BSBM19G & Math $\backslash$ Agreeli Am Good At Mathematics & 1(Agree a lot) to 4(Disagree a lot) & -0.0046 & 0.0046 \\
\hline BSBM19H & Math $\backslash$ Agree $\backslash$ Mathematics Harder For Me & 1(Agree a lot) to 4(Disagree a lot) & 0.0086 & 0.0184 \\
\hline BSBM19I & Math \AgreelMat Makes Confused & 1(Agree a lot) to 4(Disagree a lot) & 0.0048 & 0.0060 \\
\hline BSBM20A & Math $\backslash$ Agree $\backslash$ Mathematics Will Help Me & 1(Agree a lot) to 4(Disagree a lot) & 0.0079 & 0.0116 \\
\hline BSBM20B & Math $\backslash$ AgreelNeed Mat To Learn Other Things & 1(Agree a lot) to 4(Disagree a lot) & 0.0066 & -0.002 \\
\hline BSBM20D & Math $\backslash$ Agree $\backslash$ Need Mat To Get The Job i Want & 1(Agree a lot) to 4(Disagree a lot) & 0 & 0.0157 \\
\hline BSBM20F & Math $\backslash$ AgreelGet Ahead in The World & 1(Agree a lot) to 4(Disagree a lot) & 0 & 0.0069 \\
\hline BSBM20G & Math $\backslash$ AgreelMore Job Opportunities & 1(Agree a lot) to 4(Disagree a lot) & 0 & -0.0074 \\
\hline BSBM20H & Math $\backslash$ Agree $\backslash$ Parents Think Math important & 1(Agree a lot) to 4(Disagree a lot) & -0.0149 & -0.0092 \\
\hline BSBM20I & Math $\backslash$ Agreelimportant To Do Well in Math & 1(Agree a lot) to 4(Disagree a lot) & -0.0055 & -0.0059 \\
\hline BSBM25AA & Math \How Often Teacher Give YouHomework/Math & 1(Every Day) to 5 (Never) & 0.01293 & -0.0096 \\
\hline BSBM25BA & Math \How Many Minutes Spent On Homework/Math & 1(No Math Homework) to 6(More than 90 minutes) & 0.01032 & 0.0101 \\
\hline BSBM26AA & Math $\backslash$ Extra Lessons Last 12 Month $\backslash$ Mathematics & 1(Yes, to excel in class) to $3(\mathrm{No})$ & 0 & -0.0187 \\
\hline BSBM26BA & Math $\backslash$ Extra Lessons How Many Month $\backslash$ Mathematics & 1(Did not attend) to 4 (More than 8 months) & 0.01191 & 0 \\
\hline $\begin{array}{l}\text { ITAC- } \\
\text { COMM1 }\end{array}$ & Special Accommodation $\backslash$ Achievement Session & ( 1 if yes, otherwise 0 ) & & -0.0784 \\
\hline $\begin{array}{l}\text { BSDM- } \\
\text { LOWP }\end{array}$ & Mathematics Ach Too Low For Estimation & 1(not too low), o(low) & 0.19278 & 0.2607 \\
\hline
\end{tabular}

\section{DISCUSSION}

The findings of the adaptive elastic net regression are classified as home resources, breakfast habits, gender, origin and language, information and communication technologies, communication with social environment, talented teachers, mathematics achievement, homeworks and extra lessons. These could be summarized as follows: 


\section{Home Resources}

Amount of books at home (BSBG04), digital information devices (BSBG05) and study desk possession (BSBG06C) variables can be grouped as home education opportunities variables. According to the TIMSS 2015 national mathematics and science pre-report published by the Republic of Turkey Ministry of National Education, the $8^{\text {th }}$ grade students who participated in the 2015 study, 7\% of home education opportunities are "high", 54\% are "middle" and 40\% are low (Ylldirım et al. 2016). The results of this report also support the findings of this study. The success rate of $8^{\text {th }}$ grade students increased as their home education opportunities increased. These variables are important factors on the TIMSS Mathematics achievement for both countries. Students with more home education resources (amount of books, digital information devices, computer tablet, and study desk and country specific home resources) performed better overall on TIMSS compared to others, and the correlations between TIMSS and the school achievement were stronger for students had much more home education resources possession. Moreover, living in special accommodation (ITACCOMM1) separately from the family had a negative effect on the TIMSS math success of Singaporean $8^{\text {th }}$ grade students. This is an important result in terms of the effect of the family on student success in Singapore.

The findings for Turkey show some similarities to the results of the study by Kaleli-Y1lmaz and Hanci (2016). They found a relationship with TIMSS and school grades and parents' educational level but they did not come up with a gender effect. However, my results show that the family education (BSBG07A and BSBG07B) were also found to have a great effect on student success for both countries. In fact, the children's success should depend on the country's education system, not on the family's education. As long as the Ministry of National Education could provide support for families who are not capable of educational support for their children, this leads to the success of generations ongoing.

\section{Breakfast Habits}

According to Adolphus et al. (2013) and Littlecott et al. (2015) eating breakfast has a positive effect on children's cognitive performance, especially in the areas of memory and attention. Lundqvist et al. (2019) found a positive association between breakfast consumption and academic achievement among children and adolescents. The breakfast (BSBG12) was also found to be a supporter factor on the TIMSS math scores of students in Singapore.

\section{Gender}

According to the adaptive elastic net results, the gender variable (ITSEX) plays an important role in determining student success for two countries. The girls' achievement scores are less than boys for both countries. Although girls have self-confidence, sense of belonging, motivation, and liking learning they have lagged behind in transforming them into success unlike boys (Polat and Madra, 2018). In addition, as mentioned in the UNESCO 2017's "Cracking the code: girls' and women's education in science, technology, engineering and mathematics (STEM)" book, girls STEM performance can be affected from the individual level (biological and psychological factors), family and peer-level, school level and societal level. The methods offered can be summarized as individual-level that differentiated perception between genders is biological factors such as brain structure and hormones, as well as psychological factors such as interest and motivation. As with other cognitive skills, these are changeable, can be affected by training and practices, and can be developed. If parents make enough effort for the progress of girls, it is easier for girls to overcome social, economic, and cultural barriers. The education policies can build girls' interest, self-confidence, and professional expectations in STEM. Media and social media supports are needed to challenge sexual discrimination in science and to direct girls to science. In addition, social media literacy lessons should be given for girls to better benefit from digital technology.

\section{Origin and language}

The birth place of mother and father (BSBG09A and BSBG09B) variables have positive sign contrast to student born in country (BSBG10A) variable in Singapore Model. Singapore is a multi-ethnic country. About $75 \%$ of Singapore's population is Chinese and nearly $\% 25$ of the population is Malay or Indian (Ginsburg et al. 2005). Although students were born in the country, their parents can be immigrants. Since Singapore has bilingual education strategy that includes mother tongue (Chinese, Malay, or Tamil), language differences are not a problem 
on Singapore's TIMSS success. The father born in the country (BSBG09B) variable was selected in the model for Turkey. This finding was not surprising for Turkish students, because of majority (or almost all) of the students and their parents were born in Turkey. Although the students and their parents were born in Turkey, the country has multilingual and multicultural structure. This is because the country has been a migration route for centuries and has hosted many different civilizations. (Y1lmaz and Şekerci 2016). In some parts of the country, the language spoken within a family is different from the official language of the country.

\section{Information and Communication Technologies}

The Singapore's technology-oriented education system, possession of information communication technology devices (BSBG06A, BSBG06B, BSBG06E, BSBG06F), play a very important role in increasing Mathematics TIMSS achievement of Singapore. While mobile phone does not affect student achievement in Singapore, it has been observed to be effective in Turkey. According to the results of 2015 Turkish Statistical Institute (TUIK) Household Information Technology Usage Survey, 96.8\% of the households have mobile phones, $43.2 \%$ of the households have computer tablets or laptop, $25.2 \%$ of the households have desktop computer and regular internet user rate is $94.2 \%$ in the first quarter of 2015 . These rates explain the reasons for the positive effect of mobile phones on the $8^{\text {th }}$ grade TIMSS achievement in Turkey. Since internet usage is very common, internet connection (BSBG06E) has not been found to be a distinctive feature of success. The using the internet to collaboration with classmates (BSBG14C) is not a factor in mathematics $8^{\text {th }}$ grade students' TIMSS achievement of Turkey but adjuvant for Singapore's. Güler et al. (2017) examined the internet usage aims of children between the ages of 6-15 are examined. They found that, the rate of "making voice or video calls was $7 \%$. In contrast to this low rate, the 6-15 age children's rate of "using the internet for homework and learning" was $85 \%$. I found that the TIMSS scores decrease as the usage of computer tablets increases at home, school or anywhere among the Turkish $8^{\text {th }}$ grade students.

Accessing textbooks and assignments through the internet (BSBG14A, BSBG14B), communication with teacher (BSBG14D), finding info to aid in math and science (BSBG14E, BSBG14F) variables are the factors that decreased student success by the contrary of Singapore. In contrast, the using of the internet to find info to aid in math (BSBG14E) and to access textbooks (BSBG14A) are the factors that increased success. The using the internet to find info to aid in math (BSBG14E) variable has a negative effect on Singapore's mathematics TIMSS success like Turkey. Since the Singapore mathematics curriculum is not exhaustive, it allows the student to understand better in lessons, and students use technology to access textbooks. Students use ICT for practice because they get "math sense" at school. Besides, the using the internet to access textbooks (BSBG14A) is not a distinctive feature on success, because each student can access. Moreover, the TIMSS scores of students increase as the level of their education expectations (BSBG08) increase and absent days from the school (BSBG11) decrease.

\section{Communication With Social Environment}

The communication of students in school has an important role in their mental, social, and academic development. In contrast, when the results of "The sense of school belonging" items are examined, the results of my analysis support the results of the 2011 TIMSS study of Topçu et al. (2016). I found that there was a negative correlation between sense of school belonging (BSBG15C) and TIMSS mathematics achievement scores in Turkey. The like to see classmates (BSBG15D) variable also has a negative effect on TIMSS mathematics achievement for Turkey. Besides, I can conclude that students who like being at school (BSBG15A) perform worse than others in the TIMSS math exam for both countries. Students who do not like being in school have more time to study lessons instead of having fun. In order to give students "math sense" in Singapore, mathematics lesson contents are not prepared exhaustively for the basic concepts of mathematics are learned more easily (CIU 2008). This inference explains why the decrease in the opinion of "I learn a lot at school", which is among my results, causes an increase in Singapore's TIMSS math score.

According to TIMSS 2015 survey results, in Singapore, 36\% of students are every month and 6\% of students are every week exposed to student bullying. In Turkey, $26 \%$ of students are every month, $6 \%$ of them are every week suffered from student bullying (Mullis et al. 2016). Student bullying may affect the academic performance of bullied children. Akyüz (2014) has studied Mathematics Achievement in TIMSS 2011 for Turkey and Finland and has revealed that student bullying is a significant factor of the 2011 mathematics achievement of Turkey. In 
my TIMSS models, made fun of (BSBG16A), spread lies about me (BSBG16C), and threatened (BSBG16I) are decreasing factor for only Singapore's TIMSS performance; stole sth. from me (BSBG16D) is also a decreasing factor for both countries. With the development of technology, cyberbullying has become very common among adolescents recently (Gimenez-Gualdo et al. 2018). The posted embarrassing things (BSBG16H) is an example of cyberbullying. The left out of games (BSBG16B) and the posted embarrassing things (BSBG16H) variables have a negative effect on Turkish students' scores unlike Singapore's.

\section{Talented Teachers}

As Nye et al. (2004) suggests, teachers play an important role in the students' success in academic life as well as in daily life. The teacher quality is high in Singapore. Teachers are provided with training, salary arrangement and reward support (Levent and Yazıc1 2014). All teachers are trained at Nanyang Technological University, National Institute of Education. All candidate teachers are selected through interview by participants of a responsible institution (OECD 2012). In Singapore, information communication technologies are integrated into the class atmosphere through pedagogic methods by these talented teachers. In addition, another purpose of teachers is to give students math sense and provide an easy understanding of education in the lessons. Extra lessons are also provided for students had low perception. Since the education system of Singapore is pedagogical and has structured on the technology equipment, the teachers may not need to do and say interesting things for students' success. The reason for the negative effect of variables on success maybe only the unsuccessful students need these methods in Singapore. Besides, "teachers whose expectations were not known by the students (BSBM18A)", "who were thought not to say interesting things by the students (BSBM18C)", "who cannot give clear answers to the student questions (BSBM18E)" had a negative effect on Turkish Students' TIMSS achievement.

\section{Mathematics Achievement}

In Singapore, teachers who can be understood easily (BSBM18B) and can listen to what the students say (BSBM18J) have a positive effect on student achievement. In contrast, teachers who do and say interesting things about lessons (BSBM18C, BSBM18D), do various things to help students learn (BSBM18H), give information about how the students should do better when they make a mistake (BSBM18I) have a significant negative effect. In the TIMSS $20158^{\text {th }}$ grade survey, there are 9 variables for measuring student confidence in mathematics. These can be listed as usually do well in math (BSBM19A), mathematics is more difficult (BSBM19B), mathematics not my strength (BSBM19C), learn quickly in mathematics (BSBM19D), math makes me nervous (BSBM19E), good at working out problems (BSBM19F), I am good at mathematics (BSBM19G), mathematics harder for me (BSBM19H) and math makes confused (BSBM19I). Contrary to Çavdar (2015), the TIMSS 2011 study, according to the Wilson and Narayan (2016), Choi et al. (2012), Ertürk and Erdinç-Akan (2018) studies that have been investigated the continuous effect of mathematics on achievement, as students' confidence in mathematics increases, their success also increases. All variables except "I am good at mathematics (BSBM19G)" supported the result of the studies. The student's confidence in mathematics has an important positive effect on $8^{\text {th }}$ grade TIMSS math achievement. However, if the opinion that the student is good at math is decreasing, Turkish TIMSS scores are also decreasing contrary to Singapore.

My finding supports the Lee's (2013) study results that have found the students who think that they are bad in mathematics in Asia are more successful, students who think that they are good in mathematics in Europe are more successful.

The value that the student gives to mathematics perception was evaluated by 7 selected variables in the Adaptive Elastic Net model. Arıkan et al. (2016), Yavuz et al. (2017) have not found any significant relationship between the value given by Turkish students to mathematics and students' mathematics achievement scores in the TIMSS exams survey in 2007 and 2011. When the effect of the variables was examined one by one, the similar results were also found in this study. On the other hand, in Singapore, the decreasing in the expectation that more job opportunities can be obtained utilizing mathematics (BSBM20G) causes a decreasing effect on student math achievement. The parents think Math is important (BSBM20H) and being good at math is important (BSBM20I) variables have an important role in TIMSS scores in both two countries. These findings also show the negative effect of decreasing family support and students' math self-confidence on students' achievement. 
Compared to the total time, students in Singapore are getting more hours of Mathematics lessons than Turkish students (Bozkurt et al. 2019). The result is not surprising as trying out feedback or different learning methods during limited mathematics lesson hours can make students lagged behind the other $8^{\text {th }}$ class students in basic mathematics topics.

\section{Homework and Extra Lessons}

In contrast to Singapore in Turkey, decreasing the frequency of math homework (BSBM25AA) given to the $8^{\text {th }}$ grade students is a negative factor on achievement. Because of the homework given to students very often in Turkey, students may be bored, feel tired or exhausted. This may lead to diminishing the will to study, so their academic success may reduce. As stated by the Mullis et al. (2016) TIMSS 2015 report, when compared to the rates of the $8^{\text {th }}$ grade students spending more than 3 hours per week, it was seen that Singapore ( $22 \%$ rate) overtaken Turkey ( $12 \%$ rate). The rates of both countries are above the OECD average. Although the increase in the hours spent on homework, (BSBM25BA) seems to increase success in both countries in my results, the reason for Singapore's superiority in TIMSS exams cannot be explained only with this. In Turkey, homework does not play an improvement role in students' cognitive abilities because these are often repetitions of knowledge and practices in the classroom in contrast to Singapore. The mathematics lessons are given theoretical in Singapore and lesson practices are given to students as homework. Students do their homework from electronic lesson contents all schools served that are accessible to every student. In this way, students improve their cognitive abilities through the homework that utilized the information given in the class.

The attendance frequency of the extra lessons (BSBM26BA) have been found a positive effective factor in success only in Turkey. In contrast, the extra lessons last 12 month (BSBM26AA) has a negative effect on TIMSS success of $8^{\text {th }}$ grade students in Mathematics in Singapore. This result is not surprising for Singapore, where the mathematics is teaching in the class detailed and that the students only who have unsuccessful need extra lessons.

\section{CONCLUSION AND SUGGESTIONS}

The subset of the variables affecting the TIMSS scores was selected for Turkey and Singapore using adaptive elastic net regression, which is a machine learning method that enables superior results in the analysis as it applies a reduction procedure for both variable selection and minimum variance estimators. The findings show that there exists some differences regarding the selected variables affecting the TIMSS scores among two countries. These are reported below:

In Turkey, there is the children descent from different ethnic origins. Therefore, the difference between the language spoken at home and the language of the test is a problem for Turkey. As a solution, extra official language lessons can be given to students who have problems with Turkish or can be provided bilingual (English and mother tongue) education to students similar to Singapore.

Home education resources and especially books that are important for the education and development of children have also been an important factor in the TIMSS achievement of students. Encouraging students to gain reading habit can be an important strategy for increasing the TIMSS achievement of Turkey.

The high frequency of homework given to the students is not found as an effective way to reach high TIMSS scores in Turkey contrary to Singapore. As in Singapore, instead of given homework that repeats information in class, teaching contents in the class and giving homework for only practice can be a way to increase students' cognitive development and TIMSS success in Turkey.

Mathematics textbooks in Turkey are quite extensive. This reduces the student's interest in mathematics. The content of the lesson can be reduced and lesson content that improves students' cognitive abilities instead of lesson content based on memorizing can be prepared like the Singapore education system.

Singapore has a technology-oriented education system unlike Turkey, information-communication technologies play an important role in TIMSS success. Unfortunately, technology-oriented education is not enough in Turkey. 
Training talented teachers also play an important role in Singapore's exam success. According to the 2015 TIMSS results, Singapore students are the world's best students in mathematics. The Ministry of Education Singapore trains educated teachers who can use the technology pedagogically in lessons. If Turkey wants to move to a technology-oriented education system, the government should firstly raise the quality of teachers. The quality of education is directly related to the qualifications of teachers.

Overall, the findings indicate that individual, institutional, socioeconomic factors as well as technological factors are effective in the educational performances of the countries. They also show that the technology-oriented education system with talented teachers, less homework, less extensive textbooks, and lessons that improving cognitive ability, home education resources are significant parameters to construct the education policies in Turkey for obtaining higher scores in the next TIMSS exams.

\section{Funding}

The author declares that this study has no financial support. 


\section{REFERENCES}

- ADOLPHUS, K., LAWTONAND, C. L., and DYE, L. (2013). The Effects of Breakfast on Behavior and Academic Performance in Children and Adolescents. Frontiers Human Neuroscience, 7, 1-28.

- AKYÜZ, G. (2014). The Effects of Student and School Factors on Mathematics Achievement in TIMSS 2011. Education and Science. 39(172), 150-162.

- ARIKAN, S., VAN DE VIJVER, F. J. R. and YAGMUR, K. (2016). Factors Contributing to Mathematics Achievement Differences of Turkish and Australian Students in TIMSS 2007 and 2011. Eurasia Journal of Mathematics, Science \& Technology Education. 12(8), 2039-2059.

- BOZKURT, A., CIRAK-KURT, S. and TEZCAN, S. (2019). A Comparison of the Middle School Mathematics Curricula of Turkey and Singapore with Respect to the Learning Domain of Algebra. PAU Journal of Education. 48(6), 152-173.

- BREIMAN, L. (1995). Better Subset Regression Using the Nonnegative Garrote. Technometrics. 37(4), 373-384.

- ÇAVDAR, D. (2015). TIMSS 2011 Matematik Başarısının Öğrenci ve Öğretmen Özellikleri ile İlişkisi [The Relationship Between TIMSS 2011 Math Achievement and Characteristics of Students and Teachers]. Thesis (PhD). Gazi University.

- CHOI, K., CHOI, T. and McANINCH, M. (2012). A Comparative Investigation of the Presence of Psychological Conditions in High Achieving Eighth Graders from TIMSS 2007 Mathematics. ZDM. 44 (4), 189-199.

- CIU. (2008). Learning from Singapore. North Carolina: The University of North Carolina.

- DEPREN, S. K., AŞKIN, Ö. E. and ÖZ, E. (2017). Identifying the Classification Performances of Educational Data Mining Methods: A Case Study for TIMSS. Educational Sciences: Theory \& Practice. 5(10), 1605-1623.

- ERTÜRK, Z. and AKAN, O. E. (2018). TIMSS 2015 Matematik Başarısını Etkileyen Değişkenlerin Yapısal Eşitlik Modeli ile İncelenmesi [The Investigation of The Variables Effecting TIMSS 2015 Mathematics Achievement with SEM]. Ulusal Eğitim Akademisi Dergisi (UEAD). 2(2), 14-34.

- FAN, J. and LI, R. (2001). Variable Selection via Nonconcave Penalized Likelihood and its Oracle Properties. Journal of the American Statistical Association. 96(456), 1348-1360.

- FAN, J. and LI, R. (2004). New Estimation and Model Selection Procedures for Semiparametric Modeling in Longitudinal Data Analysis. Journal of the American Statistical Association. 99(467), 710-723.

- FİLIZZ, E. and ÖZ, E. (2019). Finding the Best Algorithms and Effective Factors in Classification of Turkish Science Student Success. Journal of Baltic Science Education. 18, 239-253.

- FİİZ, E. and ÖZ, E. (2020). Educational Data Mining Methods for TIMSS 2015 Mathematics Success: Turkey Case. Sigma J Eng \& Nat Science. 38 (2), 963-977.

- GiMENEZ-GUALDO, A.M., ARNAIZ-SANCHEZ, P., CEREZO-RAMIREZ, F. and PRODOCIMO, E. (2018). Teachers' and Students' Perception About Cyberbullying. Intervention Strategies in Primary and Secondary Education. Media Education Research Journal. 56(26), 29-38.

- GINSBURG, A., LEINWAND, S., ANSTROM, T. and POLLOCK, E. (2005). What the United States Can Learn from Singapore's World-Class Mathematics System (And What Singapore Can Learn from the United States): An Exploratory Study. Ed: E.Witt. WASHINGTON, DC: American Institutes for Research.

- GÜLER, H., SSAHINKAYASI, Y. and ŞAHINKAYASI, H. (2017). İnternet ve Mobil Teknolojilerin Yaygınlaşması: Firsatlar ve Sinırlılıklar [The Penetration of Internet and Mobile Information Technologies: Opportunities and Limitations]. Sosyal Bilimler Dergisi.7 (12), 186-207.

- HOERL, A. E. and KENNARD, R. W. (1970). Biased Estimation for Nonorthogonal Problems. Technometrics. 12(1), $55-67$.

- JIRATCHAYUT, K. and BUMRUNGSUP, C. (2015). A study of Adaptive Elastic Net Estimators with Different Adaptive Weights. Science \& Technology Asia. 20(3), 1-7. 
- KALELI-YILMAZ, G. and HANCI, A. (2016). Examination of the $8^{\text {th }}$ Grade Students' TIMSS Mathematics Success in Terms of Different Variables. International Journal of Mathematical Education in Science and Technology. 47(5), 674-695.

- LEE, W. O. (2013). The Development of a Future-Oriented Citizenship Curriculum in Singapore: Convergence of Character and Citizenship Education and Curriculum 2015. In Globalization and the Singapore Curriculum from Policy to Classroom. Eds: Z. Deng, S. Gopinathan And C. Kim- Eng Lee. pp. 241-260. SINGAPORE: Springer, First Edition, ISBN: 978-981-4451-56-7.

- LEVENT, F. and YAZICI, E. (2014). Singapur Eğitim Sisteminin Başarısına Etki Eden Faktörlerin İncelenmesi [Examination of Factors Affecting Success of Singapore Education System]. Journal of Educational Sciences. 39(January), 121-143.

- LitTlecotT, H. J., MOORE, G. F., MOORE, L., LYONS, R. A. and MURPHY, S. (2015). Association Between Breakfast Consumption and Educational Outcomes in 9-11-Years-old Children. Public Health Nutrition. 19(9), 15751582.

- LUNDQViST, M., VOGEL, N. E. and LEVIN, LARS-A. (2019). Effects of Eating Breakfast on Children and Adolescents: A Systematic Review of Potentially Relevant Outcomes in Economic Evaluations. Food \& Nutrition Research.63(9), 1-15.

- MARTIN, M.O., MULLIS, I.V.S. and HOOPER, M. (ed.) (2016). Methods and Procedures in TIMSS 2015. C.A., Boston: Boston College, ISBN: 978-1-889938-29-5.

- MULLIS, INA V.S., MARTIN, M. O., FOY, P. and HOOPER, M. (ed.) (2016). TIMSS 2015 International Results in Mathematics. C.A: TIMSS \& PIRLS International Study Center, Boston College.

- NYE, B., KONSTANTOPOUlOS, S. and HEDGES, L., V. (2004). How Large are Teacher Effects? Educational Evaluation and Policy Analysis. 26(3), 237-257.

- OECD. (2012). Lessons from PISA for Japan, Strong Performers and Successful Reformers in Education. Paris: OECD.

- POLAT, E. and MADRA, A. (2018). PISA 2015 ve TIMSS 2015 Işs̆ğında Türkiye'de Cinsiyete Dayalı Başarı Farkı [The Gender-Based Differences in Achievement in Light of PISA 2015 and TIMSS 2015 in Turkey]. ADV and ERG. [Online] https://www.egitimreformugirisimi.org/pisa-ve-timss-2015-bulgulari-isiginda-turkiyede-cinsiyete-dayalibasari-farki-bilginotu/ [Date accessed:1/5/2020].

- SHEN, X. and YE, J. (2002). Adaptive Model Selection. Journal of the American Statistical Association. 97(457), $210-221$

- TIBSHIRANI, R. (1996). Regression Shrinkage and Selection via the Lasso. Journal of Royal Statistical Society. 58(1), 267-288.

- TOPÇU, M.S., ERBILGIN, E. and ARIKAN, S. (2016). Factors Predicting Turkish and Korean Students' Science and Mathematics Achievement in TIMSS 2011. Eurasia Journal of Mathematics, Science \& Technology Education. 12(7), 1711-1737.

- TUIK (2013). Household Information Technology Usage Survey, 2013. İstanbul,Turkey [online] from http://tuik.gov. tr/PreHaberBultenleri.do?id=13569, [Date Accessed: 4/1/2020].

- TUIK (2015). Household Information Technology Usage Survey, 2015. İstanbul, Turkey [online] http://tuik.gov.tr/ PreHaberBultenleri.do?id=18660, [Date Accessed: 4/1/2020].

- UNESCO. (2017). Cracking The Code: Girls' and Women's Education in Science, Technology, Engineering and Mathematics (STEM). France, Paris: UNESCO.

- WILSON, K. and NARAYAN, A. (2016). Relationships Among Individual Task Self-Efficacy, Self-Regulated Learning Strategy Use and Academic Performance in A Computer-Supported Collaborative Learning Environment. Educational Psychology. 36(2), 236-253.

- YAVUZ, H. Ç., DEMIRTAŞLI, R. N., YALÇIN, S. and DIBEK, M. İ. (2017). The Effects of Student and Teacher Level Variables on TIMSS 2007 and 2011 Mathematics Achievement of Turkish Students. Education and Science. 42(189), $27-47$. 
- YILDIRIM, A., ÖZGÜRLÜK, B., PARLAK, B., GÖNEN, E. and POLAT, M. (2016). TIMSS 2015 Ulusal Matematik ve Fen Bilimleri Ön Raporu: 4. ve 8. Siniflar [The National Preliminary Report of TIMSS 2015 Mathematics and Science: $4^{\text {th }}$ and $8^{\text {th }}$ Grades]. Ankara: MEB.

- YILMAZ, F. and ŞEKERCİ, H. (2016). The Issue of Mother Tongue: Problems of Students Based on the Experience of Primary School Teachers. Journal of Qualitative Research in Education. 4(1), 47-63.

- YOO, J. E. and RHO, M. (2017). TIMSS 2015 Korean Student, Teacher, and School Predictor Exploration and Identification via Random Forests. The SNU Journal of Education Research. 26 (12), 43-61.

- YOO, J. E. (2018). TIMSS 2011 Student and Teacher Predictors for Mathematics Achievement Explored and Identified via Elastic Net. Frontiers in Psychology. 9, 1-10.

- ZOU, H. and HASTIE, T. (2005). Regularization and Variable Selection via the Elastic Net. Journal of the Royal Statistical Society. Series(B) 67, 301-320.

- ZOU, H. (2006). The Adaptive Lasso and its Oracle Properties. Journal of the American Statistical Association. 101(476), 1418-1429.

- ZOU, H. and ZHANG, H. H. (2009). On the Adaptive Elastic-net with a Diverging Number of Parameters. The Annals of Statistics. 37(4), 1733-1751. 